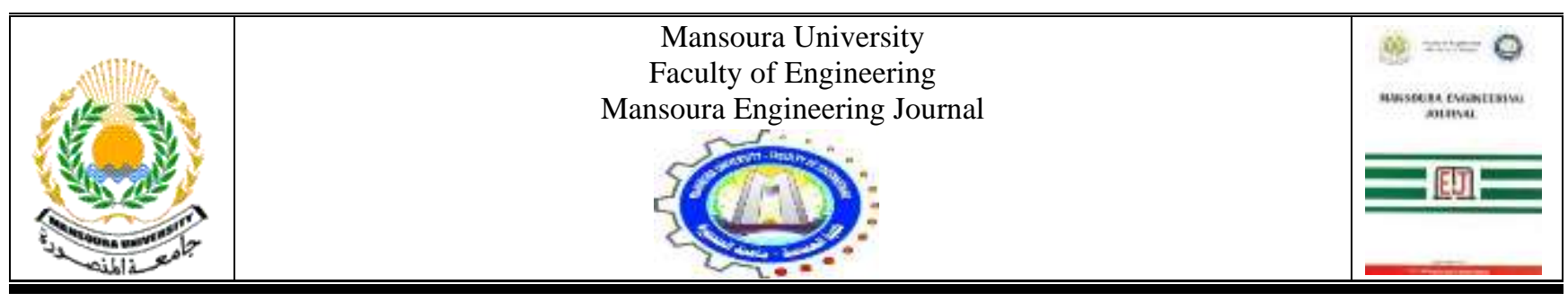

\title{
The Role of Building Technology in Reaching Architectural Design Compatible with the local Environment
}

\author{
Mai Abulhasan Omar, Lobna Abdulla Abdulfattah and Ayman Gamal Eldin Ahmed
}

$\begin{array}{lr}\text { KEYWORDS: } & \\ \begin{array}{l}\text { Compatible } \\ \text { technology, }\end{array} & \text { building } \\ \text { Local } \\ \begin{array}{l}\text { environment, } \\ \text { materials, }\end{array} & \begin{array}{r}\text { Building } \\ \text { Thermal }\end{array} \\ \begin{array}{l}\text { comfort, } \\ \text { development, }\end{array} & \text { Urban } \\ \begin{array}{l}\text { Sustainability, } \\ \text { climate, }\end{array} & \text { Hot } \\ \text { region. } & \text { Climate }\end{array}$

\section{INTRODUCTION}

$\mathrm{O}$

NE of the most important questions asked is "What are the elements that achieve sustainability and thermal comfort in the areas of a hot dry climate? Another question is, "How to make use of natural building materials to achieve the best results for the building?" The concept of the environment and its types are identified, then the climate and the elements that produce climatic regions are addressed. The climate region Egypt belongs to was clarified and how it was classified into climatic regions. Research includes knowing the extent of thermal comfort related to a

Received: (4 June 2020) - Revised: (30 August, 2020) - Accepted: (18 September, 2020)

Corresponding Author: Mai Abulhasan Omar Anani, A lecturer at the department of architecture-College of engineering-Delta High Institute for Engineering and Technology. Email: mai.anan66@yahoo.com \& meme.sanfory.103@gmail.com climate design, to achieve thermal balance that a person requires in a space to feel comfortable inside the space all the year.

In the end, building materials and their types are defined in terms of how they exist and examples. They showed the importance of using local sales materials for building, and they pointed out the importance of examples that were already erected and attracted attention and considered as environmentally friendly buildings.

Research problem lies in the fact that there is no consistency and compatibility between building materials used in construction and the surrounding environmental, climatic conditions, which is a real crisis. One of its most important elements is lacking creative values and neglecting the

Dr. Lobna Abdulla Abdulfattah Agha, Assistant professor of Architecture at the Department of Architectural Engineering, Tanta University, Tanta, Egypt.Email: lobna.agha.arch@gmail.com \&lobna.agha@f-eng,tanta.edu.eg

Dr. Ayman Gamal Eldin Ahmed Abdel Tawab, Associate professor at the Department of Architectural Engineering, Tanta University, Tanta, Egypt. Email: $\underline{a} g$ a abdeltawab@yahoo.co.uk 
functional aspects. Moreover, most areas of the Arab world are dominated by a desert climate that is characterized by drought and urbanization there requires appropriate ingredients and characteristics. How to take advantage of traditional materials in a modern way and how to provide solutions that start from the environment to preserve them and achieving selfsustainability although many compatible building technologies suitable for the local environment in the Arab world and many urban and architectural items are available.

The main aim of this study is to identify different building materials environmentally compatible and the extent of the interaction between these materials and the environment in an integrated way. Therefore, many public and private agencies concerned with the construction and urban affairs and sector in the Arab regions have begun to adopt urban properties and include them within the conditions and standards required in desert projects. Additionally, it aims to focus on the importance of the role of local building materials and sustainable urban development in the desert environment.

It also focuses on the importance of the role of local building materials and sustainable urban development in the desert environment, and to identify mechanisms that define compatible building technologies that are most appropriate for each region included within specific urban regulations and laws within a balanced framework, providing a method that starts from the presence of building materials available in each region. It leads to effective, sustainable development and helps in achieving environmental balance in desert regions. Generally, it aims to conform with the natural data and climatic factors and adapt to its hot dry climate and try to provide some criteria for building technologies (building materials) that are environmentally compatible.

The main objectives of research can be summarized as follows:

1. To create a building that achieves thermal comfort and stability and remains compatible with the outer atmosphere of climate change.

2. To access an environmentally compatible architecture that achieves sustainability with natural resources in the desert.

3. To attempt to provide criteria for designing environmentally friendly buildings in hot dry areas.

4. To know, examine and analyze the natural materials available in Egypt and how to make optimal use of them in a sustainable environmental design.

\section{METHOD}

An analytical applied method using Design Builder Program was used here because it suits the purpose of the study. This program was used to conduct simulation experiments by entering climatic data for the three areas examined in the study. It also included testing three materials in each city and providing the results of heat balance for the most important elements (roof, inside walls, outside walls in the building.

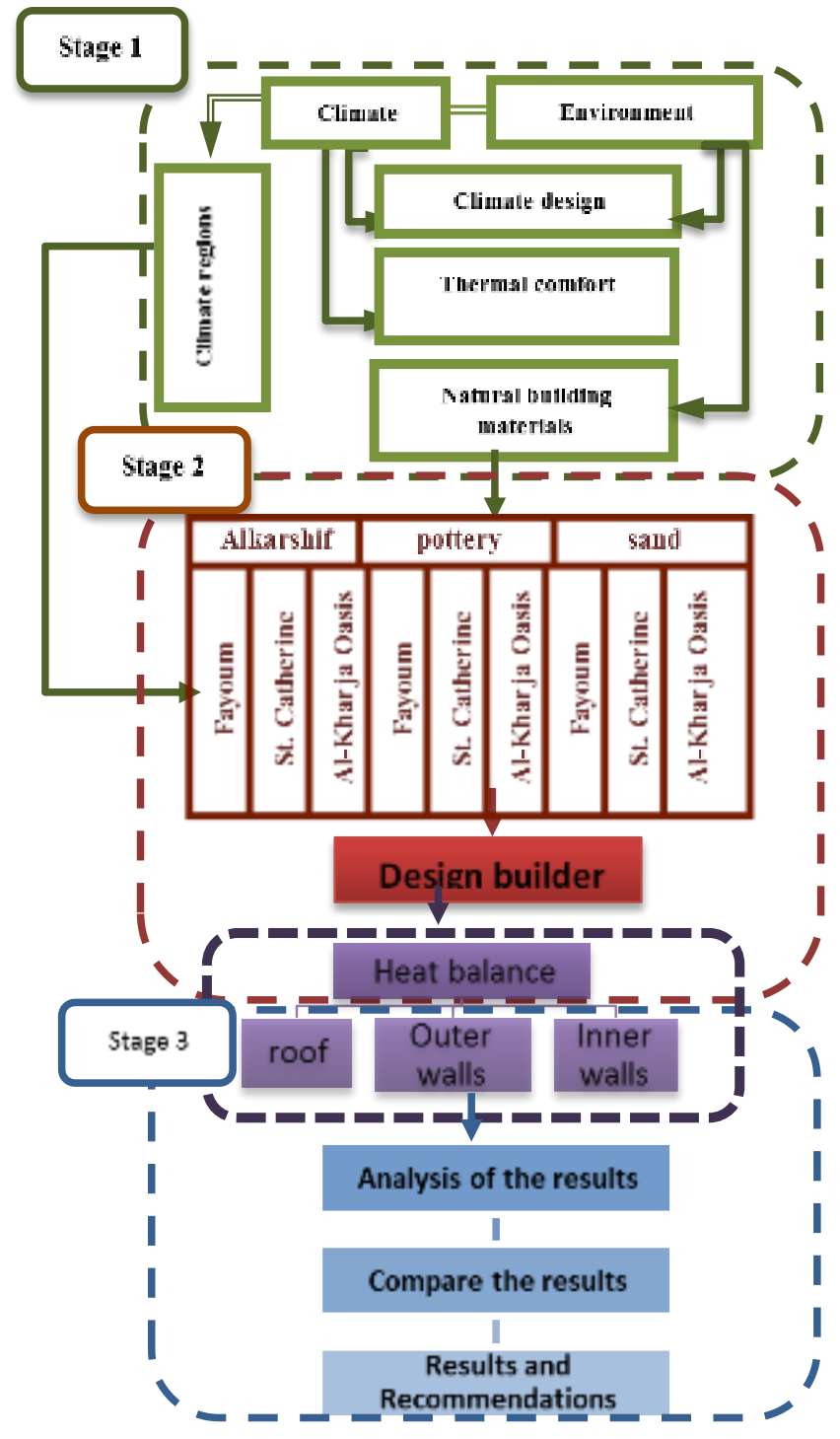

III. DEFINITION OF THE ENVIRONMENT

The word "environment" in Arabic refers to the verb (Bawa), from which the previous verb (baa) was taken, and it is concerned with the verb (Tabawa), the first: reforming the place and preparing it for the dwelling in it, and the second: the meaning of staying and living. In the Holy Qur'an, God says واذكروا إذا جعلكم خلفاء من بعد عاد وبو أكم في الأرض تتخذون من سهولها )

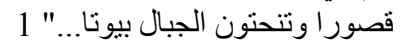

- In the dictionary of the environment it is the physical, chemical and biological context that surrounds an organism.

- The environment is defined in Webster dictionary as the climate structure, soil effect, biological factors affecting wildlife in the communities of living organisms and ultimately determining its forms and survival after the demise of life. ${ }^{2}$

In a broader sense, the term 'environment' is not used to describe the physical environment of people only, but also social as culture, language, traditions and political systems.

In general, the environment can be defined as (the environment surrounding a person, which includes all the material and non-material aspects, human and non-human, and 
this means that the environment means what is outside the human being, as it includes the assets surrounding it, air, water, land and everything surrounded by living or inanimate objects, which are the elements of the environment in which he lives, and which are considered the framework in which a person practices his life and his various activities ${ }^{3}$.

From the perspective of architects, the environment is the ultimate image of the visible environment perceived at a specific place and time. It is characterized by its own natural and homogeneous features, and is linked between the elements of the place and other natural factors that are man-made affecting the place, and that occurs after a continuous interaction, and achieving compatibility between nature and man-made for the place ${ }^{2}$.

\section{A. Types of environment}

Environment at Stockholm conference* was divided into three types:

Natural Environment: It consists of four closely related systems: atmosphere, hydrosphere, land, Biosphere.

Ecological Environment: it includes the "individual" human being, his family and his community, as well as living organisms in the biosphere.

Social environment: means the group of relationships that link a person with others, and these relationships are those that organize groups and the patterns of those relationships constitute what are known as social systems and a civilized environment4.

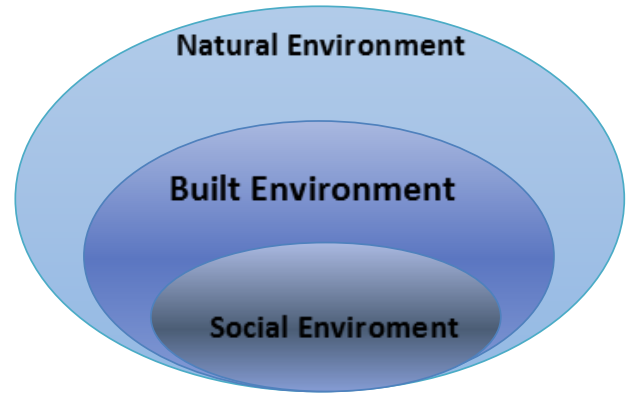

Fig. 1. Environmental system consists

Source: researcher

\section{CLIMATE}

\section{A. Climate definitions}

Climate is generally defined as the characteristics of a particular region in terms of temperatures, droughts, winds, lighting, sun brightness, cloud accumulation and fog, as well as all elements that can be measured or monitored.

The climate is divided into ${ }^{5}$

1. Marco climate: The climatic conditions recorded by the weather stations of a region in a country.

2. Microclimate: It is the climatic conditions that pertain to a small urban settlement (city or village), or even a small site around the building.

3. Indoor climate: It is the climate concerned with the interior of the building and differs from the climate outside the building.

\section{B. Climate Elements}

They are all phenomena that can be measured or monitored, in addition to some phenomena estimated or described as the weather when a sandstorm or thunderstorm occurs

1. Sun (solar radiation).

2. Air temperature.

3. Moisture.

4. Wind.

5. Rain.

6. Sometimes lightning strikes - earthquakes - dust storms are factors that affect the climate. ${ }^{6}$

\section{Climatic Regions}

The climate region is known as the part that is characterized by general climate characteristics and features that are distinct from other neighboring regions, and in which the weather conditions are similar. ${ }^{7}$

\section{A. Sections Of Climatic Regions}

A climate region is known as the part characterized by a general climate characteristics and features that are distinct from other neighboring regions, and in which the weather conditions are similar. ${ }^{7}$

\section{B. Sections of climatic regions}

Basic climatic zones have been determined and they depend largely on latitude and how close they are to the oceans and apply to areas near the sea level. These areas are ${ }^{6}$ :

1. A hot area with dry and wet regions.

2. The Mediterranean climate area.

3. An area with a moderate climate.

4. Cold climate area (Arctic climate).

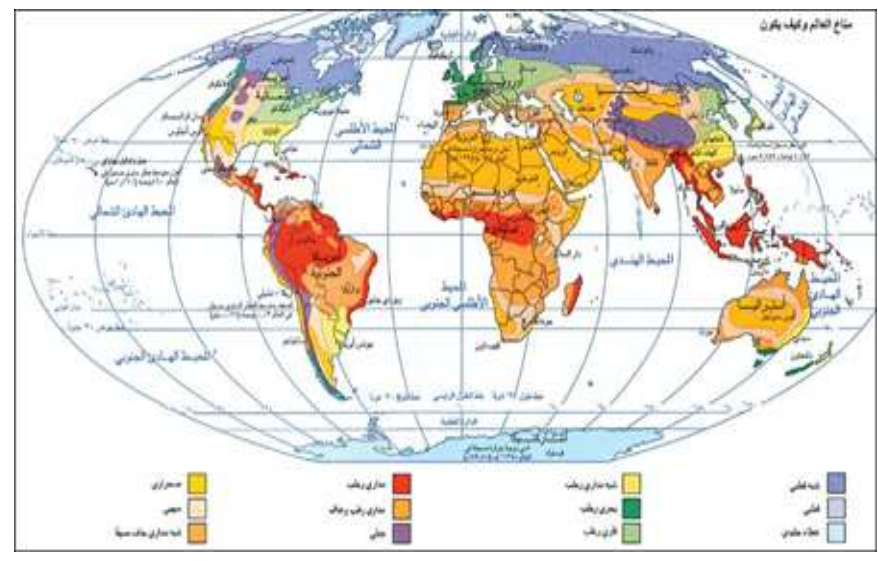

Fig. 2. CLIMATIC REGIONS

https://www.tes.com/lessons/CcwsbVWK9kdb7g/climate

Last seen: 28-8-2020 / 1:00 pm.

\section{Climatic regions of Egypt}

According to the climate classification of the Housing and Building Research Center (HBRC), Egypt is divided into eight climatic regions, as shown in Figure ${ }^{7}$ :

1. North Coast region.

2. Cairo and Delta region.

3. North Upper Egypt region. 
4. Southern Upper Egypt region.

5. East Coast region.

6. The highlands region.

7. The desert region.

8. South Egypt region.

This classification depends on temperature, humidity, wind speed, rain, solar radiation, latitude and various terrains for Egypt.

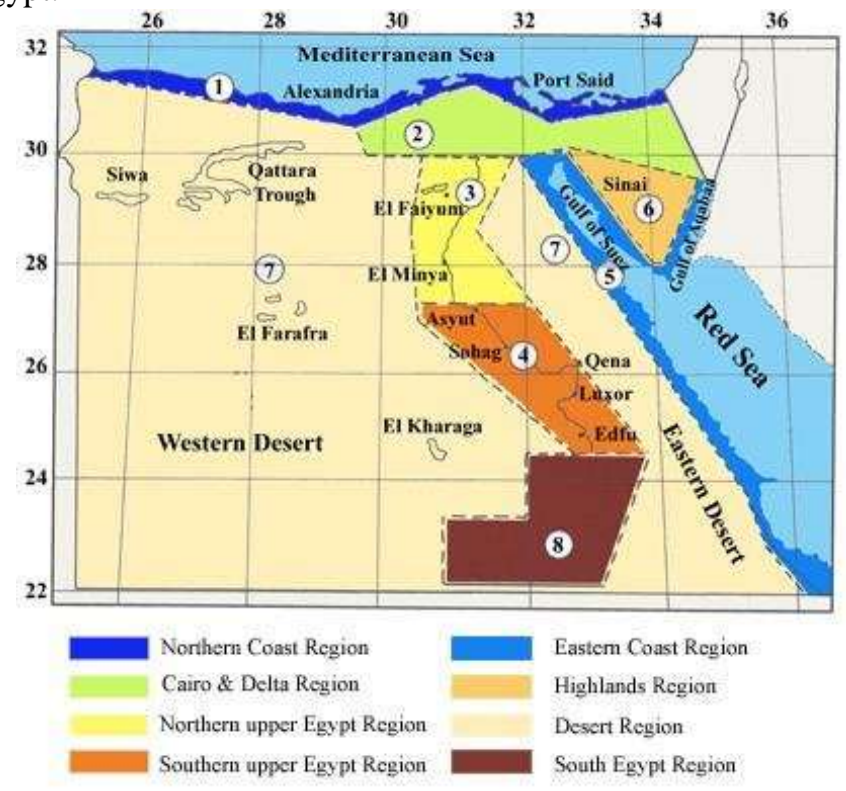

Fig. 2. CLIMATIC REGIONS OF EGYPT

https://www.researchgate.net/figure/Egypts-climatic-zones-classificationmap-according-to-housing-and-building-research_fig1_283349212 last seen $28 / 8 / 20201: 00 \mathrm{pm}$

\section{THERMAL COMFORT}

Achieving comfort is one of the primary functions of a building, and comfort refers to the resistance to the main negative elements to the climate of the surrounding area of the building, where the building is able to purify or absorb and expel the climatic factors according to its harm or benefit in the comfort of the occupant or the user.

Human comfort cannot be measured in terms of functional (physiological) factors only. One of the main requirements for this comfort is to maintain the thermal balance between the body and its environment, ensuring that the internal body temperature is preserved within a specified range regardless of the external environmental factors.

\section{A. thermal comfort concept}

The feeling of well-being and comfort differs from person to person and is not necessarily the same at all times. There are many variables that affect the sense of comfort, and therefore it is not possible to give a specific and explicit definition of comfort, as there are several definitions, including:

- American Society of Heating (ASHRAE) definition is "a state of mind in which a person expresses his or her satisfaction with the thermal environment" (ASHRAE, 2001) ${ }^{8}$.
- Professor Ole Fanger** (1967) defines thermal comfort as "a state of thermal neutrality, which is the situation in which a person prefers that the surrounding environment be at the same temperature and cold as that in which he exists and we interpret it as that environment that one cannot judge by being cold or hot, i.e. it represents a state of equilibrium Thermal in the absence of any feeling of discomfort".

- Christian Andreas Victor Hensen*** (1991) defines comfort as "a situation in which there are no strong impulses that drive the correction of the environment by adopting a specific behavior".

Accordingly, thermal comfort can be defined as a state of mind that leads to a person's sense of contentment. This satisfaction occurs only in the case of thermal balance between the body and the surrounding environment without the need to sweat in summer and shiver in winter ${ }^{9}$.

\section{Climate design}

Climate design is defined as an aspect of the internal environment design process that is concerned with providing climatic conditions that bring comfort to people at the lowest possible cost, and this definition is limited to the main goal of climate design. ${ }^{10}$

As the climatic design depends on the typical or usual weather conditions, it is usually relatively easy for a designer to obtain the necessary climatic information for any region through the various published data. Contrary to the regional climate data, information about a site's own climate is not usually readily available and is often obtained through personal observations and local experiences. ${ }^{11}$

\section{CLIMATE DESIGN LINKED TO THERMAL COMFORT}

Thermal comfort is related first to the climate design, whereas it is supposed to maintain the stability of the internal body temperature and requires reaching a temperature appropriate to the environment surrounding the human being. And it is possible to define the basic determinants of the architectural space to achieve human comfort. The basic determinants to be met include:

1) Achieving thermal comfort (treatment of heat flow and treatment of moisture levels within the architectural vacuum air).

2) Providing psychological and security comfort (providing a safe, secure vacuum that achieves the emotional connection between man and the vacuum).

3) Achieving audiovisual comfort (color treatment, natural interior lighting and noise treatment).

4) Providing comfort in the ease of internal exploitation of the architectural vacuum (the functional success of the vacuum) 12 .

Climate design must achieve $70 \%$ of the previous determinants, as climate design is related to ventilation, lighting, humidity, energy saving and harmony with the surrounding environment and the protection from sand and cold storms, thunder, rain and noise, and it has to do with the surrounding landscape in order to work as a natural insulator of noise to achieve human comfort ${ }^{13}$. 


\section{HeAt BALANCE}

Tests were conducted on the value of the heat balance of the most important elements of the building (roofs - exterior walls - interior walls), and heat balance means that it is the state in which the body temperature becomes constant and the amount of heat energy expelled by it to the surrounding (lost) medium is equal to the amount of heat that it draws from it. Any material exchanges thermal energy with the surrounding medium where it is taken (acquired) and given (lost) at the same time. ${ }^{14}$

If the heat energy lost is greater than the heat energy gained, the temperature of the material decreases, and vice versa. When the amount of heat gained becomes equal to the amount of heat lost, the temperature of the substance is established and kept, that is, it is in a state of thermal equilibrium.

\section{Building Materials}

Building materials are all items used in construction. Humans used different types of materials during different eras to build buildings, and different establishments. Throughout the ages, different types of building materials differed in terms of the nature of their presence as they were divided into ${ }^{15}$ :

1) Natural building materials: They are used as they are without treatment, such as stone, clay, reeds and plant types. They are collected and built directly with them, and they are the oldest types.

2) Treated natural building materials: Such as bricks and wood, before starting construction, they should be treated a little bit like making blocks and cutting trees.

3) Manufactured building materials: Like bricks, concrete, and steel, the natural materials go through a manufacturing stage before being used for construction.

4) Industrial building materials: glass and plastics.

In the present time, most organizations tend to use local natural materials for construction, as they are available, low cost, and benefit from local labor. The impact of environmental factors cannot be neglected, as they affect the durability and behavior of materials and thus affect the building. In other words, each region has its own materials that cannot be used in another region, where climatic characteristics can affect the materials and cause damage and a harmful impact on building materials. The materials used should be appropriate in the design, detail and nature of climatic conditions. ${ }^{16}$

Some famous examples of buildings that have been completely built with local natural building materials from the surrounding environment:
TABLE I:

EXAMPLES OF BUILDINGS WITH NATURAL MATERIALS SOURCE: RESEARCHER

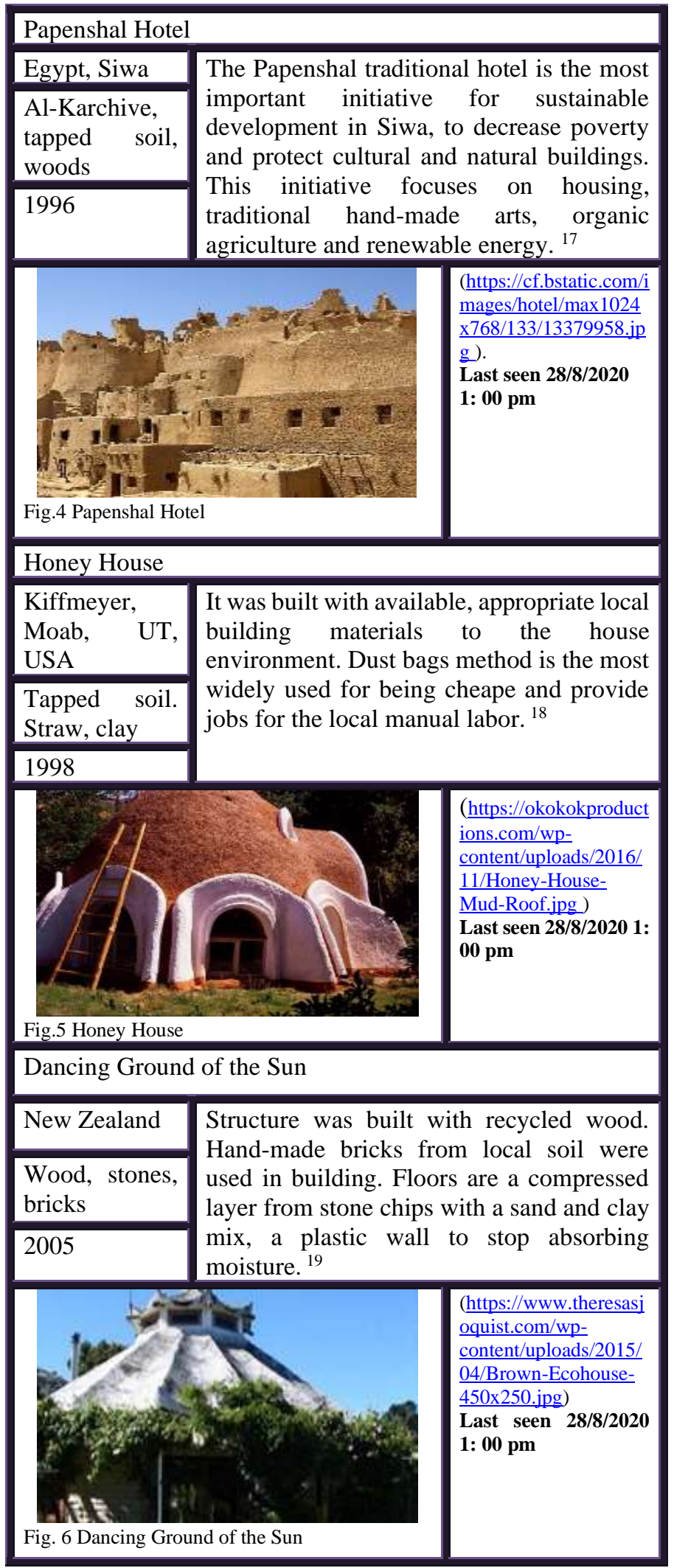




\section{A. sand}

Sandbags are made mostly of burlap, or polypropylene or other materials, and are filled with sand or dirt, and the first use of it was to make fortified walls against the enemy or for control, and sometimes it is a protective element for military buildings or gatherings of soldiers and barracks. ${ }^{20}$ Burlap and sand are inexpensive, available, and easy to find. Therefore, with some technology and architectural development, it was used to build entire houses.

TABLE 2:

Roof and wall layers for the sand case Source: researcher

\begin{tabular}{l||ll} 
U-VALUE ( W/M2-K) 1.007 & \\
\hline \hline ROOF LAYERS & $\bullet$ & $\begin{array}{l}\text { External paint layer }=4 \mathrm{~cm} \\
\text { Sandbag layer }=15 \mathrm{~cm}\end{array}$ \\
& $\bullet$ & $\begin{array}{l}\text { Inner white layer }=2 \mathrm{~cm} \\
\end{array}$ \\
\hline \hline WALL LAYERS & - & $\begin{array}{l}\text { an outer white layer }=2 \mathrm{~cm} \\
\text { cement fiber }=2 \mathrm{~cm}\end{array}$ \\
& - & $\begin{array}{l}\text { A layer of sandbags }=30 \mathrm{~cm} \\
\text { cement fiber }=2 \mathrm{~cm}\end{array}$ \\
& - Inner white layer $=2 \mathrm{c}$
\end{tabular}

TABLE 3: THE HEAT BALANCE VALUE FOR SAND Source: researcher

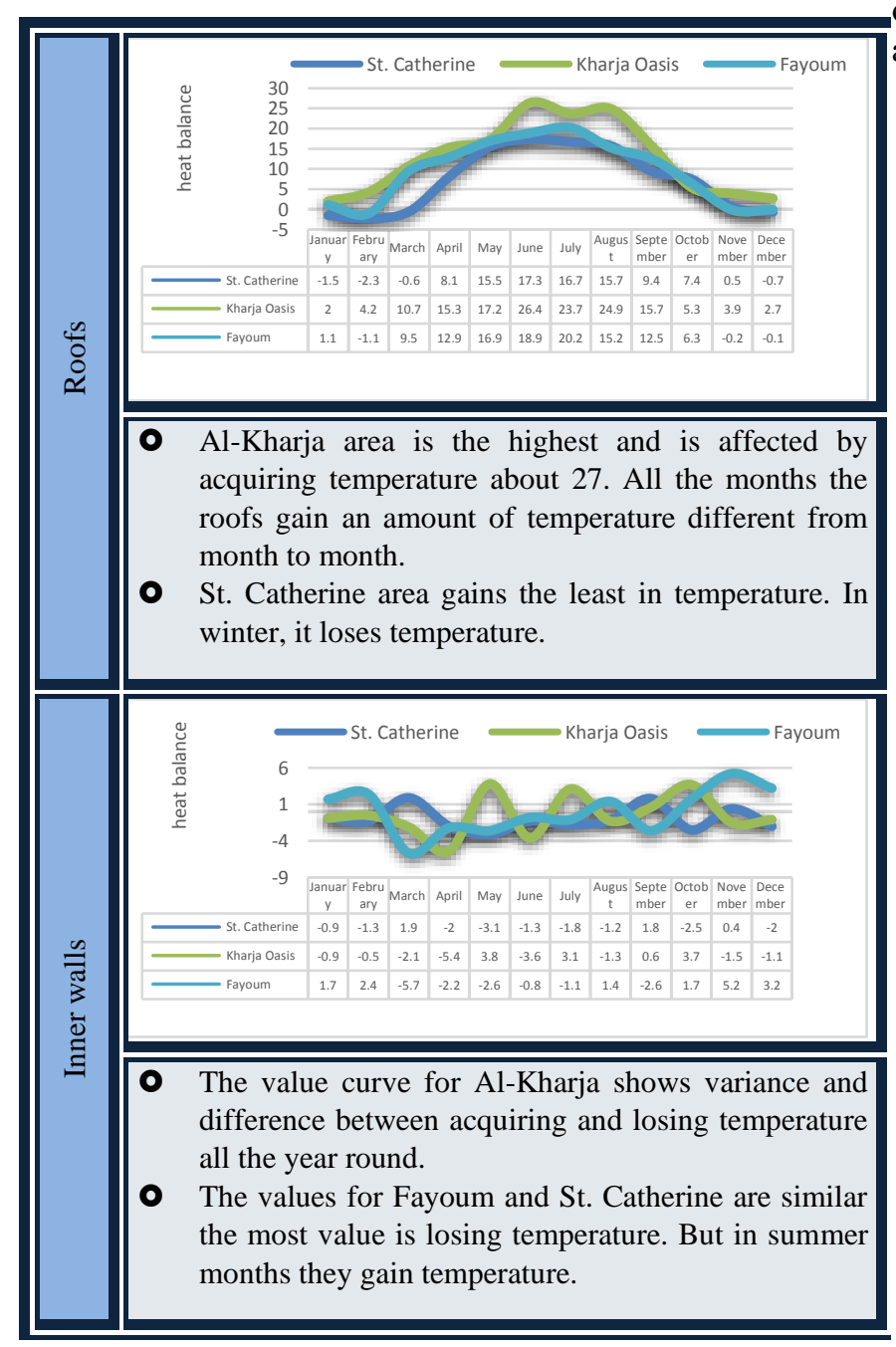

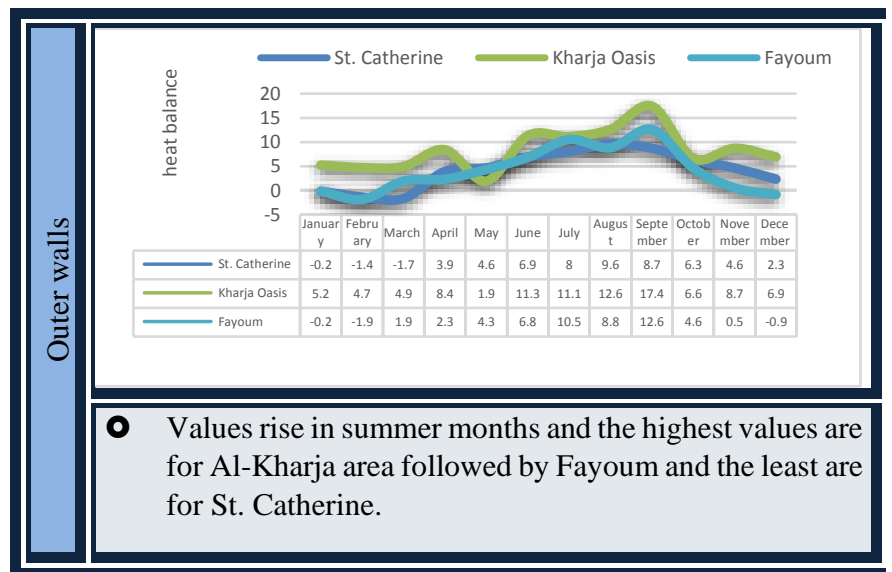

\section{B. Pottery}

Pottery is a material resulting from burning clay, and clay is considered the main material used in making pottery. The use of the pottery unit as construction in the building is considered an element of suitability of this unit for the climate in hot dry areas, as it is porous and there is air used for insulation and it takes a large time to transfer heat from outside to inside, and the general external pattern of the pottery buildings appears as an organic, compact and organic construction where its image appears to be carved in nature..$^{21}$

\section{TABLE 4}

ROOF AND WALL LAYERS FOR THE POTTRY CASE SOURCE: RESEARCHER

\begin{tabular}{|c|c|}
\hline \multicolumn{2}{|c|}{ U-VALUE $(\mathrm{W} / \mathrm{M} 2-\mathrm{K})=2.055$} \\
\hline - $\quad$ ROOF LAYERS & $\begin{array}{ll}\text { - } & \text { Outer white }=2 \mathrm{~cm} \\
\text { - } & \text { Pottery layer }=30 \mathrm{~cm} \\
\text { - } & \text { Inner white }=2 \mathrm{~cm}\end{array}$ \\
\hline - $\quad$ WALL LAYERS & $\begin{array}{ll}\text { - } & \text { outer white }=2 \mathrm{~cm} \\
\text { - } & \text { pottery layer }=30 \mathrm{~cm} \\
\text { - } & \text { inner white }=2 \mathrm{~cm}\end{array}$ \\
\hline
\end{tabular}

TABLE 5

THE HEAT BALANCE VALUE FOR POTTRY SOURCE: RESEARCHER

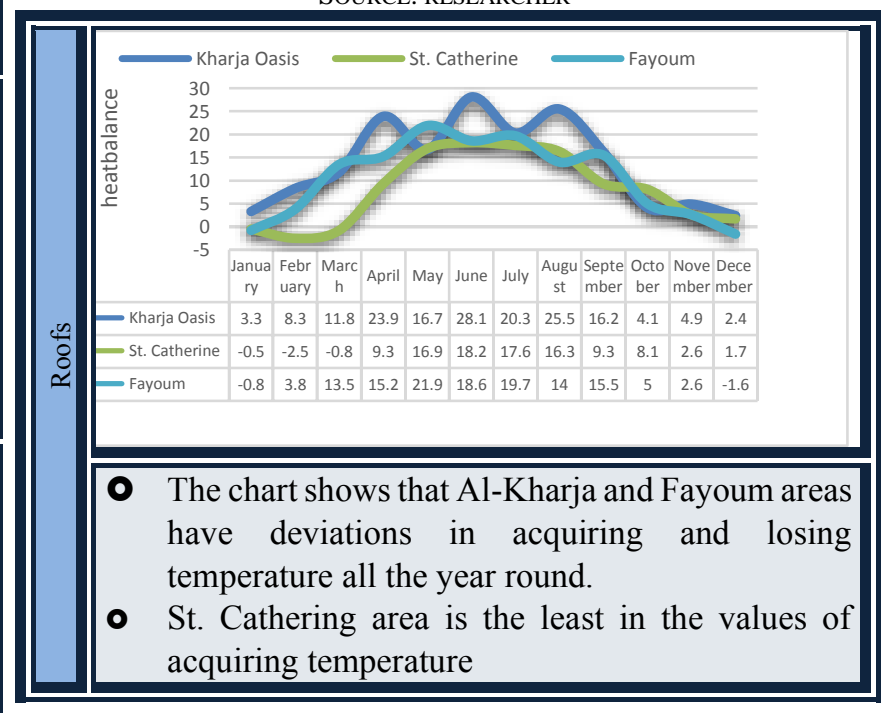




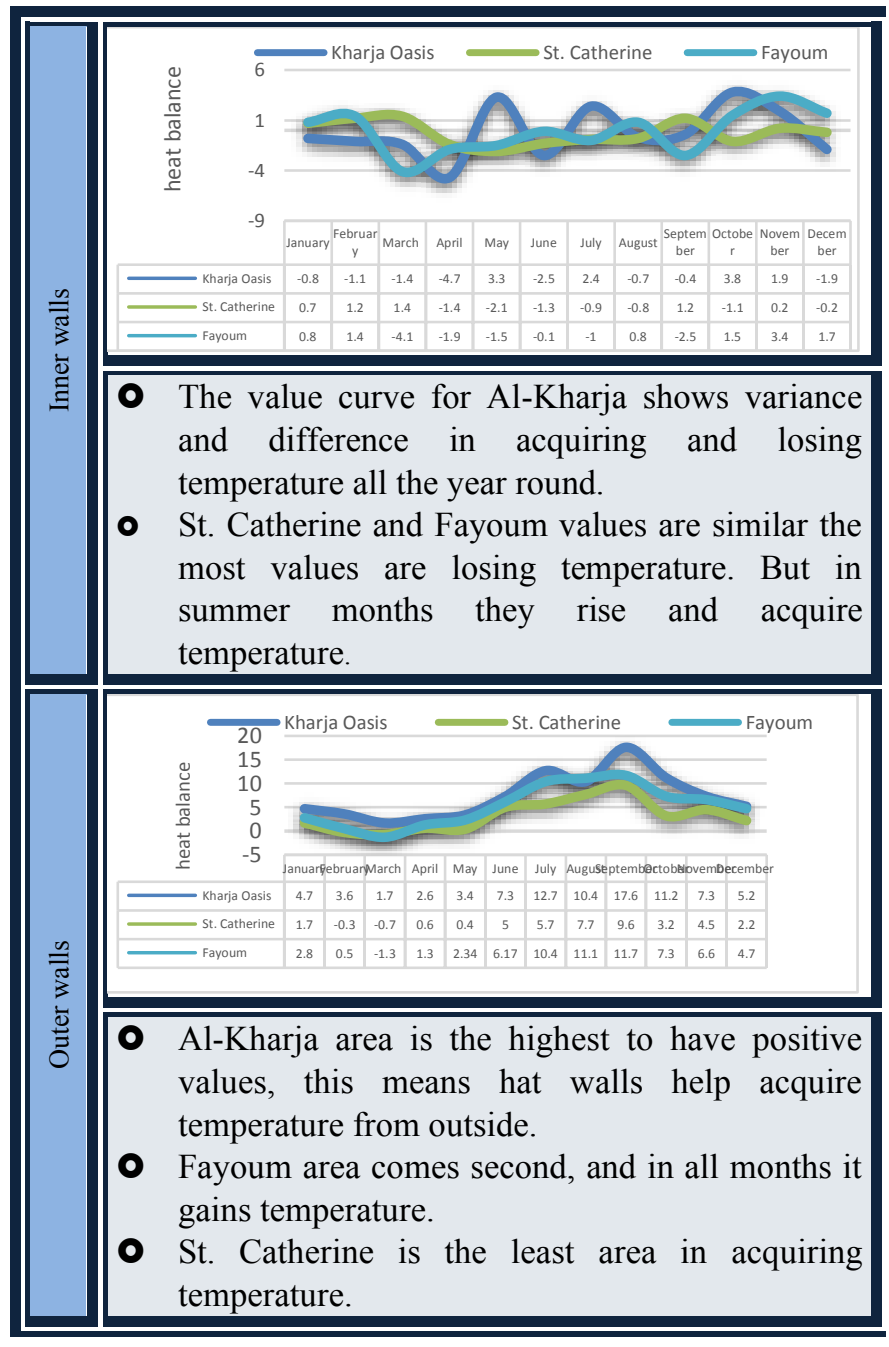

\section{C-Alkarshif}

It is a layer of salt stones found in the soil near the semisaline lake areas, or the salts that formed a burning salt layer thousands of years ago. ${ }^{22}$

Karshif is a unique building material to Siwa Oasis and is extracted from its environment. It is a layer of salt stones found in the soil near the semi-saline lake areas

This method of construction contributes to maintaining a moderate temperature inside the homes, as the homes preserve the humidity of the atmosphere during the summer and warmth during the winter season. This method of construction also ensures the mixing and harmony of the shape of the buildings with the local environment.

The thickness of the walls is from $60-80 \mathrm{~cm}$, and this thickness decreases in the upper floors where it is from 30-40 $\mathrm{cm}$, and the windows are very small holes in the ceiling of the rooms in order to keep the atmosphere inside the rooms always humid and sometimes the windows work in the form of a triangle with two windows at the top and one at the bottom.

Building using karshif has limitations that must be focused on so that it does not lead to construction problems, and to avoid any problems that the building may encounter. Local environment materials to achieve the building's goal of adapting to the environment and weather changes in summer and winter, in addition to preserving the luster and beauty of the old Siwa Oasis architecture

TABLE 6

ROOF AND WALL LAYERS FOR THE ALKARSHIFCASE SOURCE: RESEARCHER

\begin{tabular}{l|l} 
U-VALUE $(\mathrm{W} / \mathrm{M} 2-\mathrm{K})=$ & 2.055 \\
ROOF LAYERS & $\begin{array}{l}\text { Outer white }=2 \mathrm{~cm} \\
\text { Alkarshif layer }=25 \mathrm{~cm}\end{array}$ \\
WALL LAYERS & $\begin{array}{l}\text { Inner white }=2 \mathrm{~cm} \\
\text { Outer paint layer }=4 \mathrm{~cm}\end{array}$ \\
& AlKarshif layer $=25 \mathrm{~cm}$ \\
& Wool blog layer $=2.5 \mathrm{~cm}$ \\
Inner white layer $=2 \mathrm{~cm}$
\end{tabular}

TABLE 7

THE HEAT BALANCE VALUE FOR ALKARSHIF SOURCE: RESEARCHER

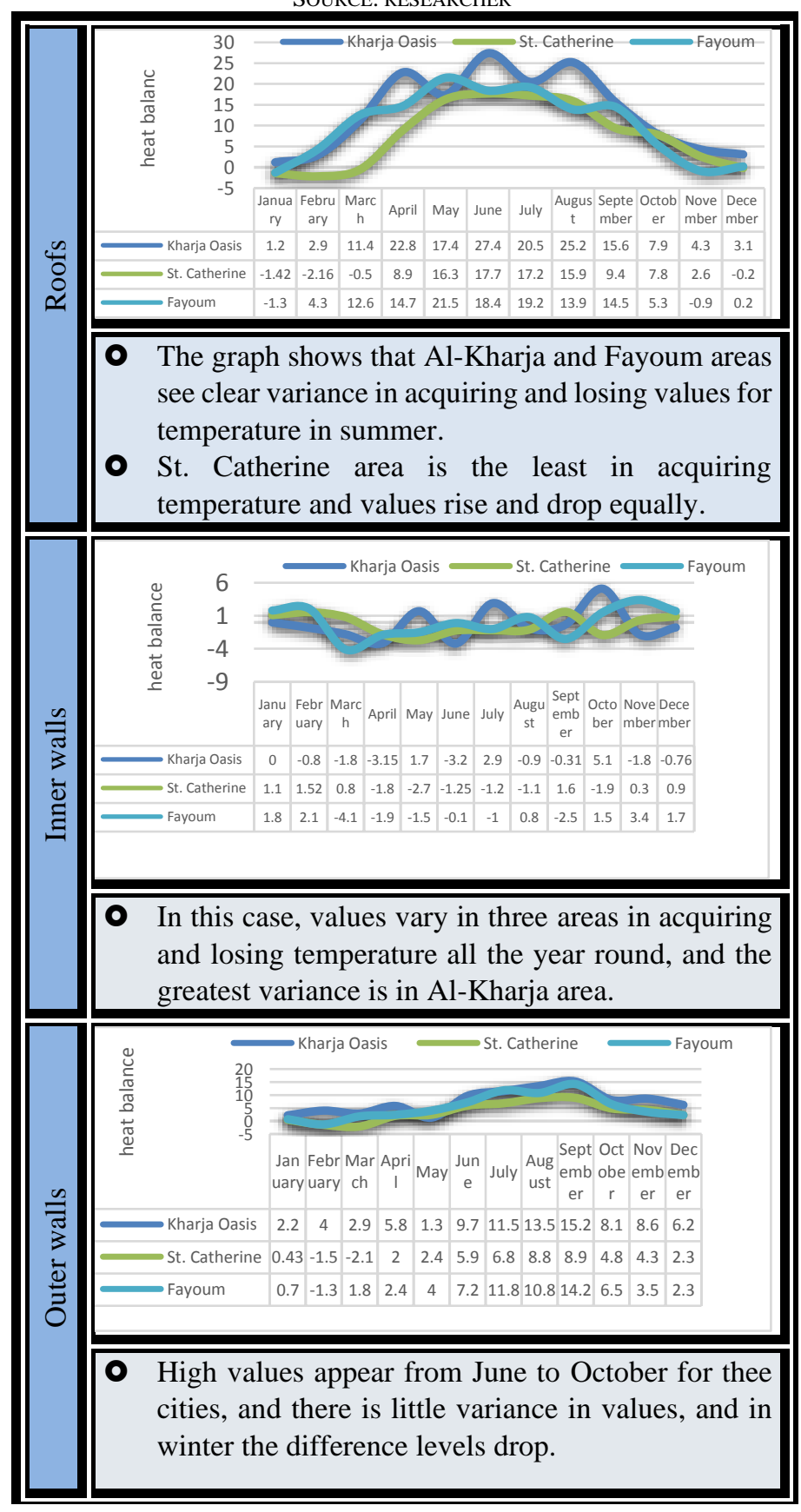




\section{RESULTS AND RECOMMENDATIONS}

This study concludes that pottery material is high in heat transfer and has a value of $2.055 \mathrm{~W} / \mathrm{m} 2-\mathrm{K}$, followed by sandbags $\mathrm{W} / \mathrm{m} 2-\mathrm{K} 1.007$ and the territory of Karshif, which is $391(\mathrm{~W} / \mathrm{m} 2-\mathrm{K})$.

A. In the city of St. Catherine:

- As for the roof, which is the element exposed to direct sunlight, sand and scrap materials should be used to build the roof because they are less heat acquiring and loss than clay.

- When looking at the values of thermal balance of the outer walls, which are considered an element exposed to the sun in a wide way, the values differ, so it is noticed that Karshif is the least to gain heat in summer, the most lost heat and the least lost heat in winter compared to sand and pottery.

- For internal walls, there is no clear difference between the amount of acquisition and loss in relation to materials, where the amount of loss (Karshif -2.7 / sand -2.5 / pottery -2.1) and in relation to the amount of acquisition (Karshif 1.5 / sand 1.9 / pottery 1.4 )

- When comparing the values, it is noted that the best material used in St. Catherine is Karshif, followed by sand, and the last is pottery.

\section{B. Fayoum City:}

- The values are considered for the materials when used in the roof. There is no noticeable variation in it. The values range from the 20.2 gain to -1.6 loss.

- When looking at the values of the thermal balance of the external walls, it is noticed that a clear difference exists between the values of the sand and the crepe and the clay materials, the thermal gain value of the clay material is 10.7 and the ones that follow the clay material 12.6 and the last of them is Karshif 14.2

- With regard to the internal walls, there is no clear difference between the amount of acquisition and loss with respect to pottery and curved materials ranging from 3.4 / -4.1 , but the amount of sand ranges between 5.2 and -5.6

- When comparing the values, it is noted that the pottery material gives the best evaluation of the acquisition and heat loss in the city of Fayoum

\section{Kharja Oasis:}

- It is clear that the pottery material values $(18.2 /-2.5)$ have a clear difference between sand and karshif materials (26.4 / 2 - 27.4 / 1.2) which are considered the same values and do not give any values for thermal loss.

- Looking at the thermal equilibrium values for the outer walls, it is clear that they do not give values for three of the test materials, and we notice that karshif is the least of them to gain heat (15.2/ 1.3), sand (17.9/ 1.9) and pottery (17.6 / 1.7)

- While the interior wall values show clear dispersion and discrepancy, sand material is $(3.7 /-5.4)$, pottery material is $(1.4 /-2.1)$ and karshif material is $(2.9 /-3.4)$
- When comparing the values, it is noted that the sand substance gives the most values that have a negative effect on the thermal balance, and the preference in choosing ranges between two materials: karshif and pottery.

\section{RECOMMENDATIONS}

1) Spreading the intellectual and architectural awareness of the importance of the environment and environmental design to produce environmentally friendly and compatibly buildings.

2) The importance of knowing the climate and its specifications for the building site before starting the design process of a building.

3) Learning how to adapt to the hot dry climate, how to design environmentally friendly buildings, so that they take into account the adaptation of the hot dry climate and adapt to it.

4) All architects and designers should know how to calculate thermal comfort and how to achieve thermal balance appropriate to each space throughout the year.

5) Taking into account the structural comfort of the building design.

6) Attention to using local natural materials for construction.

7) Determining the natural materials available in each capable region.

8) Reliance on local resources such as mud and wood and the exploitation of plant elements in the environment.

9) Paying attention to local architecture and its development and avoiding the closed box architecture.

10) Conducting more theoretical and applied studies on architectural formation on ceilings and facades in hot dry climate because of its very influential role in reducing thermal load.

11) An applicant should to conduct and offer a study that explains the sustainability of handling building materials and considers them part of the licensing requirements.

12) Conducting more theoretical and applied research of the impact of environmental and climatic factors on buildings.

13) Examine the concepts of environmentally friendly design that contribute to overcoming these climatic factors.

\section{REFERENCES}

Basic format for books:

[1] The Holy Quran, Surat No. 7, Al-A'raf, verse No.74.

[2] Jalool. A. (nd). Elements of environmental architecture design and its role in sustainable development in desert areas (case study of the city of Sakra) - Master thesis, Algeria -2014- University of Mohamed Khader Biskra - Institute of Science and Technology Department of Architecture.

[3] Omar, M. I. (2010). Introduction to Environmental Sciences. Dar Al-Kutub Al-Alami for Publishing and Distribution, 3rd edition, Cairo, p. 32.

[4] Bayan Ahmed Osman, Smart solutions in buildings and their impact on the elements of architectural and structural design, IOSR Journal of Mechanical and Civil Engineering May- Jun. 2016.

[5] Abu El-Enein, H. S. A. (1989). The Origins of Climate Geography Foundation of University Culture, Alexandria, p. 17.

[6] Al-Wakeel, S. A, \& Siraj, M. A. (2016). Climate and architecture of hot regions. 4 th edition. 
[7] Michael Allaby, The Basics of Environmental Control,the edition published in the Taylor \& Francis e-library,2002

[8] Hamazh, T. R, \& Yeang. (2002). Ecology of the sky. By Chris Abet. Mulgrave, Vic.: Images; Woodbridge: Antique Collectors' Club (distributor), 2001

[9] Standerd, A. (1981). Thermal Comfort condition in Athena.2005.

[10]Watson \& labs. (n.d). Climate design: Energy-Efficient Building Principles and Practices, Published January 1st, 1983 by McGraw-Hill Companies.

[11]Konya, A. (n.d).The foundations of design in hot regions. Translation and commentary by Dr. Ahmed El-Khatib - first edition 2011 - Cairo Anglo Egyptian Library.

[12] T. R Hamazh \& Yeang. (2001). Ecology of the sky. By Chris Abet. Mulgrave, Vic.: Images; Woodbridge: Antique Collectors' Club (distributor), 2001

[13] Yeang, K. (n.d). Ecodesign: A Manual for Ecological design.

[14] The role of facades in achieving thermal comfort in administrative buildings in Egypt.

[15]Retrieved from: https://web.archive.org/

Last seen: 28-8-2020 / 1:10 pm.

[16]Mubarak, K. (2010). Development of building materials and methods in desert architecture. Master Thesis in Archeology, specializing in Sahrawi archeology - Algeria, University of Mohamed Khidr - Biskra.

[17] Retrieved from:

https://www.archilovers.com/projects/188843/albabenshal-heritagelodge.html\#resources.

Last seen: 28-8-2020/1:10 pm

[18] Minke, G. (2006). Building with Earth, Design and Technology of a Sustainable Architecture, Kassel

[19] Retrieved from:

https://www.theresasjoquist.com/?s=Dancing+Ground+of+the+S un

Last seen: 28-8-2020/1:10 pm.

[20] Retrieved from:

https://science.howstuffworks.com/nature/naturaldisasters/sandbag1.h tm

Last seen: 28-8-2020/1:10 pm.

[21] Global Action Programme on Education for All Youth Project.

[22] Al-Khidrawi, R. K. (2012). Preserving Architectural Heritage to Achieve Sustainable Tourism Development Through Civil Society Institutions Case Studyin Siwa Oasis. Master Thesis, Ain
Shams University, Faculty of Engineering - Department of Urban Planning and Design.

* United Nations Conference on the Human Environment (Stockholm Conference): The United Nations Conference on the Human Environment (also known as the Stockholm Conference) was an international conference convened under United Nations auspices held in Stockholm, Sweden from June 5-16, 1972. It was the UN's first major conference on international environmental issues and marked a turning point in the development of international environmental politics.

** Professor Ole Fanger - (July 16, 1934 - September 20, 2006) was an expert in the field of thermal comfort and perception of indoor environments

*** Christian Andreas Victor Hensen (10 February 1835 - 5 April 1924)

\section{Title Arabic:}

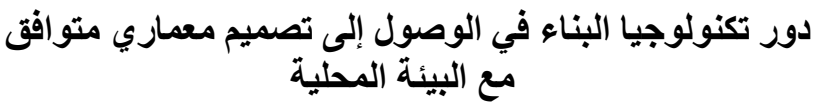

\section{Arabic Abstract:}

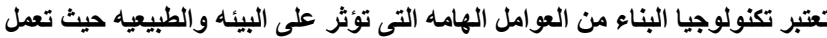

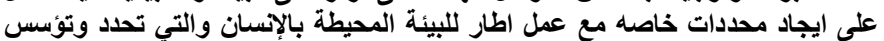

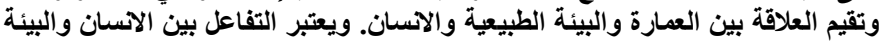

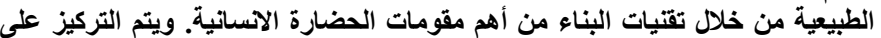

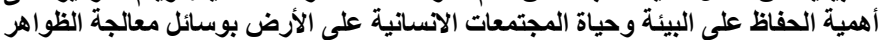

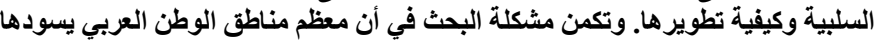

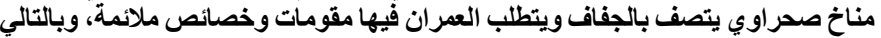

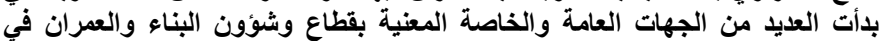

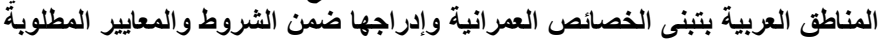

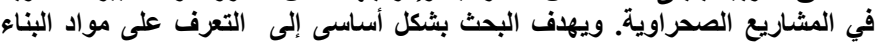
المختلفة والمتوافقة بيئيا ومدى تفاعل هذه الموادية بثلد مع البيئة بصورة الكىاملية. 